\title{
Depression, anxiety symptoms and substance use amongst sex workers attending a non-governmental organisation in KwaZulu-Natal, South Africa
}

\author{
V Poliah** iD and S Paruk \\ ${ }^{a}$ Nelson R. Mandela School of Medicine, Department of Psychiatry, University of KwaZulu-Natal, Durban, South Africa \\ *Corresponding author, email: vinolapoliah@gmail.com
}

\begin{abstract}
Background: Sex work is a high-risk occupation for mental health problems as sex workers are vulnerable to high rates of violence, sexual coercion, stigma and HIV.

Aim: To determine the prevalence of depressive and anxiety symptoms and substance use in sex workers.Method: A crosssectional questionnaire survey of all men and women attending the Sisonke health initiative, a non-profit non-governmental organisation (NGO), for sex workers was conducted over three months. A socio-demographic questionnaire, the Self Reporting Questionnaire (SRQ 20), the Patient Health Questionnaire (PHQ 9) and the WHO Alcohol, Smoking and Substance Involvement Screening Test (ASSIST V3.0) were administered.

Results: A total of 155 participants were surveyed. The prevalence of anxiety and depressive symptoms on the SRQ 20 and PHQ 9 total scores were $78.4 \%$ and $80.9 \%$ respectively. Some $40 \%$ of sex workers reported suicidal ideation in the year preceding the study. High rates of violence $(n=112,72 \%)$ and childhood abuse $(n=107,69 \%)$ were reported. The prevalence of HIV was $76.1 \%$. The lifetime prevalence of substance use for nicotine $(87.8 \%)$, alcohol (87.8\%) and cannabis (87.7\%) was high. Despite the high prevalence of psychiatric symptoms reported, only 15 (9.7\%) participants were receiving psychiatric treatment at the time of the survey.

Conclusions: The high prevalence of anxiety, depression, suicidal ideation, substance use and co-morbid HIV infection reported by sex workers and the significant treatment gap suggests an urgent need to provide an integrated health service that targets physical and mental health in sex workers.
\end{abstract}

Keywords: mental health, mental illness, sex workers, South Africa

\section{Introduction}

Sex work is a profession typically defined by its controversial nature and quasi-legal status in society. Sex work is defined as work undertaken by any person who exchanges sexual services for economic compensation such as money, drugs or alcohol., ${ }^{1,2}$

According to Rossler and colleagues sex workers are a heterogeneous population group with some sex workers working indoors, protected from violence and coercion and earning an adequate income, and others who are street-based often supporting an addiction and vulnerable to exploitation by pimps and clients. ${ }^{3}$ In South Africa the majority of sex workers fall into the latter category. Sex workers are a marginalised group in society due to the illegal nature of their work and the stigma attached to their occupation.

They are also a vulnerable population group as they are often exposed to high rates of violence from police, brothel owners and clients and they are exposed to health risks such as human immunodeficiency virus (HIV) infection and sexual harassment. ${ }^{4,5}$ Violence amongst sex workers is a common occurrence. ${ }^{3,5,6}$ Several studies have documented the high prevalence of violence amongst sex workers and its association with mental illness. ${ }^{3,5}$

The negative societal views of sex work and their psychosocial challenges force sex workers to conceal aspects of their identity and this leads to low self-esteem and self-worth. ${ }^{8,9}$ Many sex workers do not disclose their occupation to family and friends, which in turn leaves them socially isolated. ${ }^{9}$ These factors in turn predispose them to psychopathology. Specific mental health disorders that are prevalent in the sex-worker population are anxiety disorders, post-traumatic stress disorder, mood disorders and substance abuse. ${ }^{3,4,10,11}$

Despite the increased vulnerability to mental health disorders, the prevalence of depression among sex workers has varied in the international literature. Reported prevalence rates have varied from as low as $4.2 \%$ in Bangladesh, while a study in Australia reported no difference in prevalence compared with the general population, compared with a Swiss study in Zurich that found the lifetime prevalence of depression and anxiety to be $36.3 \%$ and $34.2 \%$ respectively. ${ }^{3,5,7}$ Finally a study in Nepal reported the prevalence of depression to be as high as $84 \%$ in female sex workers. ${ }^{12}$

Studies have also demonstrated high rates of substance abuse amongst sex workers, for example the study in Bangladesh reported that more than half of the sample had a substance use disorder including alcohol and other illicit drugs. ${ }^{7}$ In the Australian study the majority of sex workers were heroin dependent and one-third were either cocaine or cannabis dependent. ${ }^{5}$ Studies among arrested female sex workers in the United States of America found that $73 \%$ tested positive for cocaine use compared with $38 \%$ among females arrested for non-sex-worker-related offences. ${ }^{10}$ Substance abuse and sex work have a bi-directional relationship. Previous research has shown that sex work can be a means to finance substance dependence and substances are often used to facilitate sex work or aid in the numbing process. ${ }^{7,11}$ Substance abuse also increases the risk for sexually transmitted diseases, violence, exploitation and mental illness. ${ }^{7}$ 
In South Africa there is a dearth of literature regarding the mental health of sex workers. In the South African context, where there are high rates of HIV and violence, an understanding of sex workers' mental health needs will allow us to identify those at risk and more comprehensively address their needs.

The aim of this study was to determine the prevalence of depression, anxiety symptoms, suicidal ideation and substance use in sex workers attending a support group.

\section{Methodology: Study sites and population}

A cross-sectional study including all men and women attending the Sisonke health initiative for sex workers at four sites, namely Hibberdene, Port-Shepstone, llembe and Durban Central in KwaZulu-Natal, South Africa, was conducted. The Sisonke Health Initiative was initiated by the Sex Workers Education and Advocacy Task Force, a registered non-profit and nongovernmental organization (NGO). The data were collected from October 2015 to December 2015 by the principal investigator.

All adult sex workers aged between 18 and 65 years, attending the Sisonke Health Initiative and willing to participate, were invited to do so.

\section{Assessment instruments}

The assessment tools included a socio-demographic questionnaire, the Self Reporting Questionnaire (SRQ 20), the Patient Health Questionnaire (PHQ 9) and the WHO Alcohol, Smoking and Substance Involvement Screening Test-(ASSIST V3.0). ${ }^{13-17}$

The socio-demographic questionnaire consisted of questions relating to age, gender, income, clinical factors and other psychosocial factors relating to emotional distress such as recent experience of violence and stigma.

The SRQ 20 was developed by the World Health Organization (WHO). It is a self-rating scale that assesses the frequency and severity of 20 symptoms related to depression and anxiety on a 0 (absent) to 1 (present) scale. ${ }^{18} \mathrm{~A}$ cut off score of 7 was used to indicate the presence of depression and anxiety. The SRQ was found to be a reliable and valid instrument in a number of studies in several different cultural contexts. ${ }^{17}$

The PHQ-9 is a multipurpose instrument for screening, diagnosing, monitoring and measuring the severity of depression over the past two weeks. ${ }^{16} \mathrm{~A}$ cut off score of 5 was used to screen for the presence of depression.

The WHO Alcohol, Smoking and Substance Involvement Screening Test (ASSIST V3.0) is used to detect and manage substance use and related problems. ${ }^{15}$

\section{Statistical analysis}

Data were analysed using $\mathrm{SAS}^{\circledR}$ (version 9.4 for Windows) software (SAS Institute, Cary, NC, USA). The association between each of the potential risk variables and the presence/absence of mental health disorder (as determined by each of the SRQ20 and the PHQ) were determined by the chi-square test (or Fisher's exact test in the case of $2 \times 2$ tables or where the assumptions of the chi-square test were not met). The relative risks of the various socio-demographic variables for mental health disorder, together with their $95 \%$ confidence intervals, were calculated.

\section{Ethical considerations}

All research participants provided written informed consent. The study was approved by the Biomedical Research Ethics Committee of the University of KwaZulu-Natal and the Sisonke Health Initiative.

\section{Results}

A total of 155 participants were included in the study.

\section{Socio-demographic information}

The majority of the participants were female $(n=150,96.8 \%)$, Black $(n=147,94.8 \%)$ and $94(60.6 \%)$ were between the ages of 18 and 30 years. They were predominantly single ( $n=147,94.8 \%)$ and $101(65.2 \%)$ sex workers had not completed secondary school (below grade 12). There was no association noted between the socio-demographic characteristics and the prevalence of depression and anxiety symptoms. The sociodemographic profile of the group is summarised in Table 1.

Tables 2 and 3 compare participants' socio-demographic characteristics based on the SRQ and PHQ9 scores.

Table 1: Socio-demographic information on sex workers

\begin{tabular}{|c|c|c|c|}
\hline Variable & Category & Number & Percentage \\
\hline \multirow{6}{*}{ Age (years) } & $18-30$ & 94 & 60.6 \\
\hline & $31-40$ & 51 & 32.9 \\
\hline & $41-50$ & 6 & 3.9 \\
\hline & $51-60$ & 1 & 0.6 \\
\hline & $>60$ & 1 & 0.6 \\
\hline & Missing & 2 & 1.3 \\
\hline \multirow{3}{*}{ Gender } & $\mathrm{F}$ & 150 & 96.8 \\
\hline & M & 2 & 1.3 \\
\hline & Missing & 3 & 1.9 \\
\hline \multirow{5}{*}{ Ethnicity } & Black & 147 & 94.8 \\
\hline & Coloured & 3 & 1.9 \\
\hline & Indian & 1 & 0.6 \\
\hline & White & 0 & 0.0 \\
\hline & Missing & 4 & 2.6 \\
\hline \multirow{5}{*}{ Relationship status } & Single & 147 & 94.8 \\
\hline & Married & 4 & 2.6 \\
\hline & Divorced & 2 & 1.3 \\
\hline & Widowed & 1 & 0.6 \\
\hline & Missing & 1 & 0.6 \\
\hline \multirow{3}{*}{$\begin{array}{l}\text { Highest school grade } \\
\text { achieved }\end{array}$} & Less than grade 12 & 101 & 65.2 \\
\hline & Grade 12 & 37 & 23.9 \\
\hline & Missing & 17 & 11.0 \\
\hline \multirow{3}{*}{ Tertiary education } & No & 118 & 76.1 \\
\hline & Yes & 29 & 18.7 \\
\hline & Missing & 8 & 5.2 \\
\hline \multirow{6}{*}{$\begin{array}{l}\text { Monthly household } \\
\text { income }\end{array}$} & $<\mathrm{R} 1000$ & 92 & 59.4 \\
\hline & R1 000-R2 500 & 31 & 20.0 \\
\hline & R2 501-R5 000 & 18 & 11.6 \\
\hline & R5 001-R10 000 & 0 & 0.0 \\
\hline & $>\mathrm{R} 10000$ & 1 & 0.6 \\
\hline & Missing & 13 & 8.4 \\
\hline
\end{tabular}

*Missing refers to data where participant did not answer. 
Table 2: Socio-demographic characteristics by depression score on SRQ

\begin{tabular}{|c|c|c|c|}
\hline Characteristic & $\begin{array}{l}\text { Depressed by cut-off score on } \\
\text { SRQ } N=120 n(\%)\end{array}$ & $\begin{array}{l}\text { Not depressed by cut-off score on } \\
\text { SRQ } N=33 n(\%)\end{array}$ & $\begin{array}{c}\text { Significance (chi-square test or } \\
\text { Fisher's exact test) }\end{array}$ \\
\hline Mean age (years, SD) 18-30 & $74(61.6)$ & $18(54.5)$ & 0.42 \\
\hline \multirow[t]{2}{*}{ Female gender } & $116(96.6)$ & $32(96.9)$ & Variable not analysed \\
\hline & & & Only two male participants \\
\hline Single & $115(95.8)$ & $30(90.9$ & Variable not analysed \\
\hline Married & $2(1.6)$ & $2(6.06)$ & \\
\hline Divorced & $1(0.83)$ & $1(0.03)$ & Only four married participants \\
\hline Widowed & $1(0.83)$ & $0(0)$ & \\
\hline \multicolumn{4}{|l|}{ Schooling } \\
\hline Grade 12 & $28(23.3)$ & $9(27.2)$ & 0.44 \\
\hline Tertiary education & $24(20)$ & $4(12.1)$ & \\
\hline \multicolumn{4}{|l|}{ Income } \\
\hline$<\mathrm{R} 1000$ & $74(61.6)$ & $16(48.4)$ & \\
\hline R1 000-R2 500 & $20(16.6)$ & $11(33.3)$ & 0.12 \\
\hline R2 501-R5 000 & 14 (11.6) & $4(12.1)$ & \\
\hline R5 001-R10 000 & 0 & 0 & \\
\hline$>\mathrm{R} 10000$ & $1(0.83)$ & 0 & \\
\hline
\end{tabular}

Table 3: Socio-demographic characteristics by depression score on PHQ 9

\begin{tabular}{|c|c|c|c|}
\hline Characteristic & $\begin{array}{l}\text { Depressed by cut-off score on } \\
\text { PHQ9 } N=123 n(\%)\end{array}$ & $\begin{array}{l}\text { Not depressed by cut-off score on } \\
\text { PHQ9 } N=29 n(\%)\end{array}$ & $\begin{array}{c}\text { Significance (chi-square test or } \\
\text { Fisher's exact test) }\end{array}$ \\
\hline Mean age (years, SD) $18-30$ & $77(62.6)$ & $16(55.1)$ & 0.40 \\
\hline Female gender & $120(97.5)$ & $27(93.1)$ & $\begin{array}{c}\text { Variable not analysed as only two male } \\
\text { participants }\end{array}$ \\
\hline \multicolumn{4}{|l|}{ Marital status } \\
\hline Single & $118(95.9)$ & $27(93.1)$ & $\begin{array}{l}\text { Variable not analysed as only four married } \\
\text { participants }\end{array}$ \\
\hline Married & $3(2.43)$ & $1(3.4)$ & \\
\hline Divorced & $1(0.81)$ & $1(3.4)$ & \\
\hline Widowed & 0 & 0 & \\
\hline Schooling & & & 0.80 \\
\hline Grade 12 & $30(24.3)$ & $7(24.1)$ & \\
\hline Tertiary education & $23(18.6)$ & $5(17.2)$ & \\
\hline \multicolumn{4}{|l|}{ Income } \\
\hline$<\mathrm{R} 1000$ & $75(60.9)$ & $16(55.1)$ & \\
\hline R1 000-R2 500 & $24(19.5)$ & $6(20.6)$ & 0.42 \\
\hline R2 501-R5 000 & $16(13.0)$ & $1(3.44)$ & \\
\hline R5 001-R10 000 & 0 & 0 & \\
\hline$>\mathrm{R} 10000$ & 0 & $1(3.44)$ & \\
\hline
\end{tabular}

\section{Prevalence of anxiety and depression}

One hundred and twenty participants (78.4\%) had a score of greater than 7 suggesting depression and anxiety on the SRQ20. One hundred and twenty-three (80.9\%) participants had a score greater than 4 indicating depression on the PHQ9. Seventy-three
(48.1\%) participants scored in the moderate to severe range on the PHQ9 for current depressive symptoms. There was no significant difference between the categorised scores obtained by the two assessment tools. (Fisher's exact test: $p<0.0001$; phi coefficient $=0.35$ ). 
Table 4: SRQ depression scores and clinical characteristics

\begin{tabular}{|c|c|c|c|}
\hline Variable & $\begin{array}{c}\text { Number of participants with score } \\
\text { SRQ }>7 \text { (depressed) } \\
\text { Total }=120 n(\%)\end{array}$ & $\begin{array}{c}\text { Number of participants with score } \\
\text { on SRQ }<7 \text { (not depressed) } \\
\text { Total = } 33 n \text { (\%) }\end{array}$ & $\begin{array}{c}\text { Significance (chi-square test or } \\
\text { Fisher's exact test) }\end{array}$ \\
\hline \multicolumn{4}{|l|}{ HIV status } \\
\hline Positive ( $n=118,76.1 \%)$ & $94(78.3)$ & $22(66.6)$ & 0.26 \\
\hline Negative $(n=23,14.8 \%)$ & $16(13.3)$ & $7(21.2)$ & \\
\hline \multicolumn{4}{|l|}{ Child abuse } \\
\hline Yes $(n=107,69.0 \%)$ & $88(73.3)$ & $17(51.5)$ & $0.018(\mathrm{phi}=0.21)$ \\
\hline No $(n=47,30.3 \%)$ & $31(25.8)$ & $16(48.4)$ & \\
\hline \multicolumn{4}{|l|}{ Past psychiatric history } \\
\hline Yes $(n=42,27 \%)$ & $34(28.3)$ & $7(21.2)$ & \\
\hline No $(n=104,67 \%)$ & $79(65.8)$ & $25(75.7)$ & 0.82 \\
\hline \multicolumn{4}{|l|}{ Experience of stigma } \\
\hline Yes $(n=95,61.3 \%)$ & $79(65.8)$ & $15(45.4)$ & \\
\hline No $(n=51,32.9 \%)$ & $35(29.1)$ & $16(48.4)$ & 0.036 \\
\hline \multicolumn{4}{|l|}{ Experience of Violence } \\
\hline Yes $(n=112,72.3 \%)$ & $91(75.8)$ & $20(60.6)$ & \\
\hline No $(n=38,24.5 \%)$ & $25(20.8)$ & $13(39.3)$ & $0.044(\mathrm{phi}=0.17)$ \\
\hline \multicolumn{4}{|c|}{ Experience of police harassment } \\
\hline Yes $(n=106,68.4 \%)$ & $87(72.5)$ & $18(54.5)$ & 0.13 \\
\hline No $(n=46,29.7 \%)$ & $33(27.5)$ & $13(\# 9.3)$ & \\
\hline \multicolumn{4}{|l|}{ Lifetime substance use } \\
\hline Yes $(n=129,83.2 \%)$ & $101(84.1)$ & $27(81.8)$ & 0.93 \\
\hline No $(n=10,6.5 \%)$ & $8(6.6)$ & $2(6.0)$ & \\
\hline
\end{tabular}

Table 5: PHQ 9 depression scores and clinical characteristics

\begin{tabular}{|c|c|c|c|}
\hline Variable & $\begin{array}{c}\text { Number of participants with } \\
\text { depressed score on PH Q } 9 \\
\text { Total = } 123 n(\%)\end{array}$ & $\begin{array}{c}\text { Number of participants with score } \\
\text { on PHQ } 9 \text { not depressed } \\
\text { Total = } 29 n(\%)\end{array}$ & $\begin{array}{l}\text { Significance (chi-square test or } \\
\text { Fisher's exact test) }\end{array}$ \\
\hline \multicolumn{4}{|l|}{ HIV status } \\
\hline Positive $(n=118,76.1 \%)$ & $93(75.6)$ & $22(75.8)$ & 0.57 \\
\hline Negative $(n=23,14.8 \%)$ & $17(13.8)$ & $6(20.6)$ & \\
\hline \multicolumn{4}{|l|}{ Child abuse } \\
\hline Yes $(n=107,69.0 \%)$ & $90(73.1)$ & $15(51.7)$ & $0.042(\mathrm{phi}=0.17)$ \\
\hline No $(n=47,30.3 \%)$ & $32(26)$ & $14(48.2)$ & \\
\hline \multicolumn{4}{|l|}{ Past psychiatric history } \\
\hline Yes $(n=42,27 \%)$ & $34(27.6)$ & $7(24.1)$ & \\
\hline No $(n=104,67 \%)$ & $82(62.6)$ & $21(72.4)$ & 0.51 \\
\hline \multicolumn{4}{|l|}{ Experience of stigma } \\
\hline Yes $(n=95,61.3 \%)$ & $82(66.6)$ & $11(37.9)$ & $0.012(\mathrm{phi}=0.22)$ \\
\hline No $(n=51,32.9 \%)$ & $36(29.2)$ & $15(51.7)$ & \\
\hline \multicolumn{4}{|l|}{ Experience of Violence } \\
\hline Yes $(n=112,72.3 \%)$ & $93(75.6)$ & $17(58.6)$ & 0.091 \\
\hline No $(n=38,24.5 \%)$ & $27(21.9)$ & $11(37.9)$ & \\
\hline \multicolumn{4}{|c|}{ Experience of police harassment } \\
\hline Yes $(n=106,68.4 \%)$ & $85(69.1)$ & $19(65.5)$ & 0.99 \\
\hline No $(n=46,29.7 \%)$ & $38(30.8)$ & $8(27.5)$ & \\
\hline \multicolumn{4}{|l|}{ Lifetime substance use } \\
\hline Yes $(n=129,83.2 \%)$ & $104(84.5)$ & $22(75.8)$ & 0.44 \\
\hline No $(n=10,6.5 \%)$ & $9(7.3)$ & $1(3.4)$ & \\
\hline
\end{tabular}


Forty-seven participants (30.3\%) had a lifetime suicide attempt in the past and 62 (40\%) had suicidal ideation in the past year.

\section{Prevalence of substance abuse}

One hundred and twenty-nine (83.2\%) respondents admitted to lifetime substance use. The most commonly used substances were alcohol ( $n=136,87.8 \%)$, tobacco $(n=136,87.8 \%)$ and cannabis $(n=135,87.7 \%)$.

\section{Psychiatric treatment}

Forty-two (27.1\%) and 15 (35.7\%) respondents reported receiving psychiatric treatment previously or were currently receiving psychiatric treatment respectively. One hundred and eighteen (76.1\%) of the respondents reported that they were HIV positive, and eighty (67.8\%) sex workers were on antiretroviral treatment at the time of the survey. Tables 4 and 5 summarise the SRQ 20 and PHQ 9 scores with different clinical variables such as HIV infection and child abuse.

\section{Experience of stigma, violence and child abuse}

Ninety-five $(61.3 \%)$ participants indicated that they had experienced stigma as a result of their work and a 112 (72.3\%) respondents indicated that they had experienced violence in the course of their work. One hundred and six (68.4\%) participants indicated that they had been harassed by the police services. One hundred and seven (69.0\%) respondents reported a history of childhood abuse.

\section{Discussion}

There are several key public health findings of this study. They include the high prevalence of anxiety symptoms, depression, suicidal ideation, HIV infection and substance use amongst the sex workers. In addition the sex workers' socio-demographic profile is reflective of a highly vulnerable group that has high levels of childhood sexual abuse, violent experiences and stigma.

\section{Demographic characteristics}

Several previous studies have reported that participants were generally between the ages of 18 and 30 years, female and of a lower educational level. ${ }^{3,5,7,19}$ This is consistent with the current study, where the majority of participants were also between the ages of 18 and 30 years, of female gender (96.8\%) and $65.2 \%$ had an educational level lower than grade 12 . The findings of the profile of sex workers being predominantly female, young, single, lower educational level and unemployed is thus consistent with the literature. ${ }^{3,5,7,19}$ The lack of association between these socio-demographic factors and depression or anxiety is also generally consistent with the literature, except for the study by Hengartner and colleagues in Bangladesh which reported an association between age and mental health among female sex workers. ${ }^{3,5,7}$ This possibly suggests that other factors such as violence, HIV and other stressors may be more influential on emotional disturbance than demographic factors.

Studies examining partner status and monthly income of sex workers have demonstrated conflicting results. A study in Zurich, Switzerland revealed that sex workers earned on average 4688 euros per month (R82 958 in 2016) and 51.8\% had a stable partner; however, a study in Bangladesh (a developing country) reported that $76.8 \%$ were single and earned an average of 9666 Bangladeshi Taka (R1 969 in 2016) a month. ${ }^{3,7}$ The results from this current study are more in keeping with results from developing countries. This discrepancy in demographic characteristics between developed and developing countries further demonstrates the heterogeneous nature of the population, which may in turn influence mental health issues.

\section{Prevalence of anxiety and depression}

The prevalence of mental health disorders (78.4\%) and (80.6\%) among respondents completing the SRQ 20 and PHQ 9 respectively is alarming and a stark contrast to the South African Stress and Health study in the Western Cape, which reported that the lifetime prevalence rates of anxiety disorders were $15.8 \%$ and depressive disorders $9.8 \%$ in the general population. ${ }^{20}$ The prevalence in the current study is more than quadruple that of the general population based on this estimate. This is possibly explained by factors such the high rates of violence and stigma experienced by sex workers (also reported in this study) and the stressful nature of their work but needs further exploration. ${ }^{6,9,12,19}$

Alternatively, the anxiety and depressive scores in this study may also be inflated due to methodological factors. This study was based on a screening tool and not a full diagnostic interview, which might have been more specific. There are, however, no South African epidemiological studies using screening tools that have assessed prevalence of depression and anxiety in the general population with which to compare this study.

Whilst prevalence rates vary internationally, this current study's results on prevalence of anxiety and depression were consistent with results from developing settings such as Nepal. ${ }^{12}$ Living and working conditions of sex workers in these developing countries are similar and this may account for the more consistent findings.

Whilst $67.8 \%$ of the $76.1 \%$ of HIV-infected sex workers were on antiretroviral treatment for HIV, only 15 sex workers were currently receiving psychiatric treatment despite the high rate of self-reported symptoms. This suggests a treatment gap in the mental health care needs of this very vulnerable group. There is a need for provision of mental health screening by NGOs, which may have tended to focus on sexually transmitted diseases and contraception in the past. Earlier screening and intervention for this vulnerable group may also decrease risks such as substance use and suicide, which are associated with untreated mental illness. The rate of stigmatisation experienced by this group may also inhibit help-seeking behaviour and thus medical practitioners need to develop greater sensitivity and awareness of sex workers' unmet mental health needs. ${ }^{9}$

The rates of suicidality reported in this study $(30.3 \%$ attempts and $40.0 \%$ ideation) were higher than previous studies such as the $19 \%$ prevalence in Goa (India). ${ }^{23}$ This could be a reflection of the higher levels of psycho-social distress experienced or may be influenced by other psychosocial factors such as social support, stigma and medical factors such as HIV status in the South African setting, and needs further research.

\section{Prevalence of substance use}

The prevalence of lifetime substance use in this study is supported by the literature, which has reported high rates of substance abuse disorders in similar cohorts. ${ }^{2}$ The relationship between mood and anxiety disorders and substance use is complex, with high co-morbidity rates. ${ }^{24}$ An explanation for this high co-morbidity is the concept of a bi-directional relationship where one disorder fosters the other. ${ }^{25}$ Other explanations are shared neurobiological pathways or shared genetics. ${ }^{25}$ The prevalence of substance use is of concern as those sex workers who abuse substances are more likely to indulge in risky sexual behaviour or be exploited. 


\section{HIV status and anxiety and depression symptoms}

The 2016 UNAIDS Gap report estimated that the adult HIV prevalence in South Africa is $19.2 \%$, however the prevalence rates vary between regions and the highest rate is found in KwaZulu-Natal. ${ }^{21}$ It should be noted that the prevalence in the current study sites of KwaZulu-Natal is $40 \%$, particularly among young females.

The prevalence of HIV in sex workers in South Africa is estimated to be $59.6 \%$. This is almost three times the rate for the general population. ${ }^{22}$ Thus the finding of $76.1 \%$ in the current study is alarming and suggests the need for more intensive prevention programmes in this group.

Numerous studies have concluded that sex workers who reported being HIV infected or indulging in HIV risk behaviour are more likely to have psychopathology. 6,12,26,27 In contrast this study found no association between HIV infection and anxiety and depressive symptoms. This may be related to the increasing support surrounding HIV and the advent of antiretroviral treatment, which has altered the outcome of HIV in South Africa. In addition the support offered by NGO support groups to HIVinfected individuals may negate the negative life consequences of the diagnosis.

\section{Role of child abuse, violence and stigma}

Studies have reported that child abuse, especially sexual abuse, is positively associated with sex work, and child abuse is associated with an increased lifetime risk for depression. ${ }^{28-30}$ Therefore child abuse increases the risk for depression and may increase the risk for choosing sex work itself. In keeping with the literature, this study found a high prevalence of child abuse and those women who experienced child abuse were more likely to be depressed and anxious. This highlights the need to review the management of child abuse victims to decrease potential longterm complications of the abuse.

Our study also demonstrated a high prevalence $(n=112,72.3 \%)$ of violence experienced by sex workers in the course of their work, and an association with depression and anxiety symptoms. The high rates of violence and association with depression and anxiety are consistent with the literature. ${ }^{4,12,19}$ The relationship between violence and mental illness is complex. It is unclear whether the experience of violence itself can cause mental disorders or that those with mental illness are more vulnerable and more likely to experience violence. ${ }^{31}$ Although sex workers are at risk for violence they are often ignored and criminalised in public and occupational health policies. The police services and other relevant stakeholders need to be educated and the safety needs of sex workers should be considered when formulating relevant policies.

\section{Limitations}

There are several limitations to this study. The first limitation is the cross-sectional design, which precludes causal reasoning. A second limitation is that a convenience sampling method was used rather than a community sample and all the sex workers were from one NGO. The sample may be biased as sex workers seen at an NGO may be those in greater distress or it could imply that the support received from the NGO decreases symptomatology. Thus the sample is limited in generalisability. A further limitation is that brief screening tools were used and not a diagnostic clinical interview, which is more sensitive. Other limitations were that a self-report questionnaire was administered, which may bias results through reduced self-awareness and social desirability. The questionnaires included questions on somatic symptoms, and the high prevalence of HIV in this population could falsely elevate positive answers to questions related to somatic complaints. Finally, the findings relating to substance use are limited as only lifetime use was assessed and the specific patterns of substance use need to be further analysed.

\section{Conclusion}

This study demonstrated that there is a high prevalence of anxiety symptoms, depression, suicidal ideation, lifetime substance use and HIV infection among the sex worker population attending an NGO programme in KwaZulu-Natal. There was also a lack of mental health care provision despite respondents being part of a support group. There were also high levels of violence, child abuse and stigmatisation, which may contribute to mental health disorders. This illustrates the need to increase awareness among NGOs and health practitioners regarding the mental health needs of this vulnerable population to close this treatment gap.

This study suggests that further research could assess for risk factors to better prevent the high rates of emotional distress reported.

\section{Supplementary material}

Supplemental material for this article can be accessed here http://dx.doi.org/10.1080/20786190.2016.1272247.

\section{ORCID}

V Poliah (D) http://orcid.org/0000-0002-4254-4909

\section{References}

1. Bernstein E. Intimacy, authenticity and the commerce of sex. Chicago, IL: The University of Chicago Press; 2007. https://doi.org/10.7208/ chicago/9780226044620.001.0001

2. Heravian A, Solomon R, Krishnand G, Vasudevan CK, Krishnan $A K$, Osmand $T$ et al. Alcohol consumption patterns and sexual risk behavior among female sex workers in two South Indian communities. Int. J. Drug Policy. 2012;23(6):498-504.

3. Rossler W, Koch $U$, Lauber $C$, et al. The mental health of female sex workers. Acta Psychiat. Scan. 2010;122(2):143-52.

4. Jung $\mathrm{Y}$, Song J, Chong J, et al. Symptoms of post-traumatic stress disorder and mental health in women who escaped prostitution and helping activists in shelters. Yonsei Med. J. 2008;49(3):372-82.

5. Romans SE, Potter K, Martin J, et al. The mental and physical health of female sex workers: a comparative study. Aust N Z J Psychiatry. 2001:35:75-80.

6. Sherwood AJ, Grosso A, Decker RM, Peitzmeier S, Papworth E, Diouf $D$, et al. Sexual Violence against female sex workers in The Gambia: a cross-sectional examination of the associations between victimization and reproductive, sexual and mental health. BMC Public Health. 2015;15(270)

7. Hengartner MP, Islam MN, Haker $\mathrm{H}$, et al. Mental health and functioning of female sex workers in Chittagong Bangladesh. Front Psychiatry. 2015;6(176)

8. Hochschild A. The managed heart: Commercialization of human feelings. 2nd ed. Berkeley: University of California Press; 1983.

9. Wong S. What are the mental health seeking behaviors of female sex workers [dissertation]. Northampton, MA: Smith College School for social work; 2009.

10. Yacoubian GS, Urbach JB, Larsen $\mathrm{KL}$, et al. A comparison of drug use between prostitutes and other female arrestees. J Alcohol Drug Educ. 2002;46(2):12-25.

11. Roxburgh A, Degenhardt L, Copeland J. Post-traumatic stress disorder among female street-based sex workers in the greater Sydney area Australia. BMC J. 2006;6(24). doi: 10.1186/1471-244X-6-24.

12. Sagtani RA, Battani S, Adhikari BR, et al. Violence, HIV risk behavior and depression among female sex workers of eastern Nepal. Bio Med J. 2013;3(6):e002763. doi: 10.1136/bmjopen-2013-002763. 
13. World Health Organization. Collaborative study on strategies for extending mental health care. User's guide to the self-reporting questionnaire. Geneva: Author; 1974.

14. Spitzer RL, Kroenke K, Williams JB. Validation and utility of a selfreport version of PRIME-MD: the PHQ primary care study. JAMA. 1999;282(18):1737-44. https://doi.org/10.1001/jama.282.18.1737

15. World Health Organization Assist Working Group. The alcohol, smoking and substance involvement screening test (ASSIST): development and feasibility. Addict J. 2002;97(9):1183-94.

16. Kroenke K, Spritzer RL, Williams JBW. The PHQ-9: validity of a brief depression severity measure. J Gen Intern Med. 2001;16(9):606-13.

17. Araya R, Wynn R, Lewis G. Comparison of two self administered psychiatric questionnaires (GHQ-12 and SRQ-20) in primary care in Chile. Soc Psychiatry Psychiatr Epidemiol 1992;27:168-73. https://doi. org/10.1007/BF00789001

18. Sartorius N, Janca A. Psychiatric assessment instruments developed by the World Health organization. Soc Psychiatry Psychiatr Epidemiol. 1996;31(2):55-69.

19. Wang B, Li X, Stanton B, Fang X, Yang H, Zhao R, et al. Sexual coercion. HIV-related risk and mental health among female sex workers in China. Health Care of Women Int. 2007;28(8):745-62.

20. Herman AA, Stein D, Seedat S, et al. The South African Stress and Health (SASH) study: 12 month and lifetime prevalence of common mental disorders. S Afr Med J. 2009;99:339-44.

21. Shahmanesh M, Wayal S, Cowan F, et al. Suicidal behavior among female sex workers in Goa India: The silent epidemic. Am J Public Health. 2009;99(7):1239-46.

22. Mellor R, Lovell A. The lived experience of UK street based sex workers and the health consequences : an exploratory study. Health Promot Int. 2011;27(3):311-22.

23. Lemert EM. Social pathology. New York, NY: Mc Graw-Hill; 1981.
24. Robins LA, Regier D. Psychiatric disorders in America: the epidemiologic catchment area study. New York, NY: The Free Press; 1991.

25. Quello SB, Brady KT, Sonne SC. Mood disorders and substance use disorder: a complex comorbidity. Sci Pract Perspec. 2005;3(1):13-21. http://dx.doi.org/10.1151/spp

26. Ulibarri MD, Roesch S, Rangel MG, et al. "Amar te Duele" ("Love Hurts"): sexual relationship power, intimate partner violence, depression symptoms and HIV risk among female sex workers who use drugs and their non-commercial, steady partners in Mexico. AIDS and Behavior 2015;19(1):9-18. https://doi.org/10.1007/s10461-014-0772-5

27. Colibazzi T, Hsu TT, Gilmer W. Human immunodeficiency virus and depression in primary care: a clinical review. Prim Care Companion J Clin Psychiatry. 2006;8:210-1.

28. Brown J, Cohen P, Johnson J, et al. Childhood abuse and neglect: specificity of effects on adolescent and young adult depression and suicidality. J Am Acad Child Adolesc Psychiatry. 1999;38(12):1490-6. https://doi.org/10.1097/00004583-199912000-00009

29. Stoltz JM, Shannon K, Kerr T, et al. Associations between childhood maltreatment and sex work in a cohort of drug-using youth. Soc Sci Med. 2007;65(6):1214-21. https://doi.org/10.1016/j. socscimed.2007.05.005

30. Spatz Widom C, DuMont K, Czaja SJ. A prospective investigation of major depressive disorder and comorbidity in abused and neglected children grown up. Arch Gen Psychiatr. 2007;64(1):49-56. https://doi. org/10.1001/archpsyc.64.1.49

31. Canadian Mental Health Association. Ad Hoc working group on women, mental health, mental illness and addictions. Making the links between violence, trauma and mental health. Toronto: Author; 2009 March. 